\title{
Mobile Participation: Exploring Mobile Tools in E-Participation
}

\author{
Maria A. Wimmer, Rüdiger Grimm, Nico Jahn, and J. Felix Hampe \\ University of Koblenz-Landau, Institute for IS Research, Koblenz, Germany \\ \{wimmer, grimm, jahn, hampe\}@uni-koblenz.de
}

\begin{abstract}
In this contribution, we investigate the use of mobile technology in eparticipation contexts and we define grounds for mobile participation. Mobile participation (mPart) requires the support by tools comprising mobile digital client equipment, mobile access to the Internet, and service support of the related communication. This allows for new types of engagement of citizens in political decision-making at any time wherever citizens physically are. Different participation scenarios require different types of mPart tools. Information gathering, opinion polls, posts to political discussions in social media and in standard e-participation platforms, quick feedback forms, and group and event cooperation are some examples of participation scenarios, which we regard as mPart applications. In this paper, we examine different projects exploiting mobile technology for citizen participation - with a focus on e-participation - and we describe mPart applications and related tools that are developed and evaluated by the authors in a project. The mPart tools are embedded in a layered mPart architecture that allows a flexible integration of tools over an underlying secure communication infrastructure. The architecture serves as a reference architecture for integrating mPart tools.
\end{abstract}

Keywords: Mobile participation, mPart, e-participation, mPart tools, mPartAPI framework.

\section{Introduction}

Mobile phones have reached a penetration of $125 \%$ in Europe in 2009. Also the smartphone penetration is growing more and more. However, main use of mobile and in particular smartphone technology is currently recognized in private consumer use. While different attempts of introducing mobile technology in government contexts are known for nearly a decade (so-called m-government), mobile features are not so extensively exploited in e-participation contexts. This is astonishing especially since e-participation is striving for reaching out widely to citizens, and mobile technology is widespread in many developed and even in some developing countries.

Some e-participation projects have begun to allow smartphones to have access to their communication services. However, these are only a few, and the integration is rather ad-hoc. There is no standard strategy or architecture to build up mobile participation with respect to important requirements such as user-friendliness, 
scalability, security, and seamless cooperation with other participation means. We will use the acronym 'mPart' in short for 'm-participation' or 'mobile participation'.

In order to allow mPart tools to be integrated in a flexible way in different eparticipation contexts, we suggest an architecture that separates the user functions from an underlying communication infrastructure, especially from the Internet. The architecture is based on an mPart-API framework that provides well defined interfaces to the user tools as well as secure communication channels on top of the underlying infrastructure. The architecture provides a reference framework for integrating various mPart tools into a common architectural environment.

The paper is structured as follows: Chapter 2 investigates the state of the art of eparticipation literature. Chapter 3 provides an overview of related work on important $\mathrm{mPart}$ projects and their tools. Chapter 4 outlines the project and mPart applications with related research aims of an interdisciplinary project on communication, media and politics. The mPart tools we developed are described in chapter 5, together with a report of initial responses by users. Conclusions and an outlook on further research are given in chapter 6 .

\section{Setting Grounds for Mobile Participation: Foundations and Related Work on E-Participation}

As a generic and widespread understanding, e-participation is referred to as the use of Information and Communication Technologies (ICT) in political participation (see e.g. $[11,12,18,23])$. Macintosh argues that innovative tools and technology provide people with the capacity to participate and influence political decision-making [10]. Scholars investigating e-participation have made an attempt to structure and systematize the field of study through frameworks (e.g. [18, 23]) and differentiation among separate e-participation areas, such as information provision, consultation, deliberation, mediation, petitioning, spatial planning, participatory budgeting, etc. (see e.g. 26, 27]).

An important evolution of the field has been observed since the revolution of the Internet as a participatory web, where everyone can communicate through Web 2.0 technologies [7]. The potential of using electronic means to reach the wider citizenry opened up new possibilities for political participation via electronic means [13]. Since then, a number of e-participation tools have been developed in various projects through the support of the European Commission and through governments of different countries. An assessment of such programs and projects to spur innovation and to advance solutions for citizen participation via online means in different e-participation areas is e.g. available in [16, 23, 28]. Also, the United Nations have defined an eparticipation index along their annual e-government surveys, which 'assesses the quality and usefulness of information and services provided by a country for the purpose of

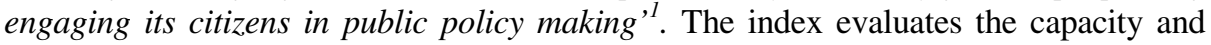
willingness of a State to explore 'deliberative, participatory decision-making in public

\footnotetext{
1 http: / / unpan3.un.org/egovkb/egovernment_overview/ eparticipation.htm (last access: 24/03/2013).
} 
policy' and whether a State reaches the objectives of 'its own socially inclusive governance program ${ }^{2}$. In the 2012 survey, Germany scored 0.7632, while Netherlands and South Korea reached the maximum of 1.000 [26, p. 134].

E-participation is also driven by technology development to support citizen participation in political decision-making. A categorization of ICT tools supporting eparticipation endeavors is e.g. given in [21, 23]. Tambouris et al distinguish e.g. among rather simple tools such as weblogs and web portals and more sophisticated consultation platforms, argument visualization tools and natural language interfaces. Technologies include e.g. messaging, semantic web, filtering methods and ontologies. In a study the authors performed 2007 on nineteen EC funded research projects of the field seven projects using mobile technologies have been identified [23]. Half a decade later, social media on the one hand and the use of mobile technologies on the other hand, have become prime means for interaction among citizens and governments in e-government and e-participation initiatives ${ }^{3}$. Recent EUROSTAT data indicate that more than half of the Internet users in Europe post to social media ${ }^{4}$.

While mobile government has reached attention as an extension or supplement of e-government [24], mobile participation has so far not reached wide attention as a concept. We therefore define mobile participation (or m-participation, in short mPart), as an extension of the concepts of e-participation - relying on above described foundations of e-participation. mPart refers to the extensive use of mobile technologies and mobile applications in e-participation contexts. Nowadays, Internet, broadband access and mobile phones are more widespread in Europe. In 2012, Eurostat reports an internet penetration in households of $76 \%$ in EU27, with Germany reaching $85 \%$; broadband access being recorded with $82 \%$ in EU27 and 82 $\%$ in Germany ${ }^{5}$. Statistics on mobile phone penetration showed already in 2009 a penetration of $125 \%$ in EU27 and of $137 \%$ in Germany ${ }^{6}$. Also the use of smartphones is catching up quickly $-47.6 \%$ of people in the EU5 (UK, Spain, Italy, France and Germany) are reported to use a smartphone in Q1 2012, with Germany scoring last among these top 5 with $41 \% .^{7}$ Hence, the provision of mobile applications to engage citizens in policy processes and democratic decision-making of

2 ibid.

3 e.g., see publications in collective volume in [4] and in the International Journal of Electronic Government Research (IJEGR), volume 8, issue 3 in 2012.

4 http: / / epp.eurostat.ec.europa.eu/cache/ITY_PUBLIC/4-18122012AP / EN/4-18122012-AP-EN. PDF (last access 24/03/2013).

5 ibid.

6 Figures calculated based on numbers of population

(http: / / epp. eurostat. ec . europa. eu/tgm/table.do?tab=table\&init= $1 \&$ language $=$ de\&pcode $=\operatorname{tps} 00001 \& p l u g i n=1)$ and mobile phone contracts

(http: / / epp. eurostat.ec.europa.eu/tgm/table.do?tab= table\&plugin=1\&language=de \&pcode=tin0 0059) in 2009 http: / / epp. eurostat.ec.europa.eu/cache/ITY_PUBLIC/ 4-18122012-AP / EN/4-18122012-AP-EN. PDF (last access 24/03/2013).

7 http://www.onbile.com/info/mobile-penetration-in-europe/ (last access 24/03/2013). 
States through mobile phones and smartphones is a natural and consequent evolution. To set the grounds for mobile participation, the next section investigates the use of mobile applications, tools and technologies in e-participation contexts of existing projects.

\section{The Use of Mobile Technology in Government Projects: An Investigation of the Current State of Projects}

Mobile technology has been explored in several projects of e-government and eparticipation. Among the first projects funded in the scope of framework program 6 of the EC, use-me.gov researched mobile government solutions around 2005. Its aim was to advance three crucial developments for mobile solutions: (1) an Open Service Platform for Mobile Government meeting the most critical usability, interoperability and scalability requirements as well as supporting shared use between public organizations and respective departments, (2) Comprehensive Business Models for Mobile Government compiling interests and roles of relevant stakeholders and correlating their roles and interests in distinct service and business scenarios, and (3) Recommendations for Service Planning including aspects of technology, standards and business operation to serve as an example for "others" when planning similar services $[1,15]$.

After use-me.gov, several projects have investigated the usage of mobile technology for providing on-the-spot information to governments such as damages on infrastructure in cities, where photos are made with mobile phones and are then sent to government sites via MMS or emails through smartphones or through uploads to a web site. The most known project in this regard is FixMyStreet in $\mathrm{UK}^{8}$. Also in Germany, similar examples exist such as Märker Brandenburg ${ }^{9}$ or "Sag's uns" of the city of Cologne, which is part of the city's mobile app ${ }^{10}$. The main features of the mobile part of these solutions are MMS or email communication to a government site with a server in the backend to integrate the mobile communication entries into the government solution of complaints management. Some sites are now beginning to integrate mobile access via smartphones (e.g. Cologne's app).

Besides reporting on damages in public spaces and other misconceptions on infrastructures of a city, cities are also launching mobile apps to provide information about the city and for tourists via smartphones. Examples to name but a few are: the Cologne service app, which provides up-to-date information and options for contacting the city with questions or feedback by the citizens ${ }^{11}$; various apps for visitors to the London city (either for download before visiting or accessible through numerous free wireless networks in the city of London) ${ }^{12}$; or the Stuttgart App, which

http: / /www. fixmystreet. com/ (last access 28/03/2013).

9 http: //maerker. brandenburg. de/brandenburg (last access 28/03/2013).

${ }^{10}$ http: / /www. stadt-koeln. de/1/verwaltung/10425/ (last access 28/03/2013).

${ }^{11}$ Ibid.

12 http: / / www. visitlondon. com/traveller-information/gettingaround-london/london-maps-and-guides / apps (last access 28/03/2013). 
provides citizens and visitors with relevant information about the city and its tourism and traffic, as well as some e-government services ${ }^{13}$.

With the evolution of open government data, a vast amount of mobile apps have evolved to provide users of smartphones information about cities or particular aspects of public interest. A good example of providing such mobile apps based on open government data is apps for Vienna with the objective to providing citizens, tourists and businesses with relevant information ${ }^{14}$. To spur the developments of the use of open government data in Germany, a contest was launched to bring forward mobile apps for informing citizens and businesses on issues of interest. The Apps4Deutschland brought forward 77 apps (among which many are for smartphones) providing useful information and services to citizens and other users by building on open government data sets ${ }^{15}$. There are many more examples where governments are providing their data to enable added-value services via smartphones to citizens. An overview of examples in the US is e.g. given in [2].

It is to be noted that most of afore mentioned solutions are largely targeting egovernment contexts, while the use of mobile apps and tools in the context of eparticipation is still rare. Examples of such projects are Padgets and urbanAPI, which are briefly introduced hereafter (both funded in framework program 7 of the EC).

PADGETS (Policy Gadgets Mashing Underlying Group Knowledge in Web 2.0 Media) ${ }^{16}$ introduces the concept of Policy Gadgets (Padgets). These are applications on top of web 2.0 technology to describe and control the interaction between a user's web software and others. The project targets integration of this concept in the established social media platforms to acquire a large number of people and uses social platforms for new services. It thereby also integrates smartphone technology for the interaction among citizens and policy makers [5].

urbanAPI (Urban Agile Policy Implementation) targets and uses virtual representations of planning decisions. Models of the real world display ideas about spatial planning. These models are 3D-models of blocks of houses and 2D-maps for visual representation of socioeconomic activity and a region-wide development simulation addressing urban growth and change. Mobile communication services allow the exploration of communication traces, describing human sojourn and activity patterns. ${ }^{17}$

To conclude, searching for projects of e-participation employing mobile technology shows that this development is still in its infancy. The few projects we came across do employ mobile technology, even though not all fully focus on eparticipation. Moreover, there is no standard strategy or architecture to build up mobile participation with respect of different challenges such as user-friendliness, acceptance, extensibility, scalability, seamless cooperation with other participation means, etc. To date, mobile tools are integrated rather in an ad-hoc manner However, the penetration of mobile phones and the trends towards more mobile access to services demands for much more research and investment in developing tools and

\footnotetext{
13 http: / / www . stuttgart. de/item/show/168768 (last access 28/03/2013).

${ }^{14}$ http: / / data.wien.gv . at/apps / (last access 28/03/2013).

15 http: / /apps4deutschland. de/category/apps / (last access 28/03/2013).

16 http : / / www . padgets . eu (last access 25/03/2013).

17 http: / / www . urbanapi . eu (last access 2013-06-03).
} 
applications for mobile participation. The State of Rhineland-Palatinate has therefore launched a project where different research disciplines are to work together to foster developments of mobile participation among others. The project is introduced in the next chapter.

\section{The Research Initiative 'Communication, Media and Politics' and Its mPart Project in the State Rhineland-Palatinate}

In the period of 2012-2015, the State Rhineland-Palatinate is supporting a new research strand at the University of Koblenz-Landau, which addresses "Communication, Media and Politics" (KoMePol). The initiative brings together different research disciplines to study various concepts of the use of media in politics and how communication is impacted by the use of a particular media type. Finally, modern ICT and the use of mobile communication facilities are explored and studied in e-participation contexts. The initiative is also investigating the building of trust in communicating via innovative media in political contexts (directly or indirectly). The participation of social science, political theory and psychology allows to do research on trust in political systems and their actors. The participation of computer science and communication theory enables studying phenomena of trust in computer systems and communication via mobile devices, mobile communication infrastructures and open networks. The initiative is divided into ten sub-projects, which all help to achieve the accomplishment of the overall research focus. These ten sub-projects are:

1. "Political communication via smartphone" targeting the question of how political information is consumed by the citizen in everyday life.

2. "Para-social Relationship to political actors" studying the impact of trust in the popularity of politicians.

3. "Mobile participation of citizens with protection of privacy" designing tools and services for mobile participation systems that respect privacy and security needs in order to allow the users to trust the technical system for mobile participation.

4. "Televised Debates in Germany" studying recipients real-time feedback while watching televised debates. Research targets are knowledge about politicians' argumentation templates and the impact at recipients' side.

5. "Mobilization of right-wing parties against Europe" focusing on the impact of right-wing parties activities on citizens.

6. "Personalization of political communication" investigating the change of relevance of a single political person and a whole party.

7. "Moral misbehavior of politicians" addressing the sacrifice of cooperativeness empowered by politicians' behavior and reports of them.

8. "Representation, Democracy and Trust" examining the type and relevance of interaction relationships, based on Web 2.0 technology, between a representative and citizens.

9. "Statistical and semantic analysis of political communication in social media" aiming to develop computer-based methods, which push transparency in political communication. 
10. "Usage motives for of social media" targeting motives of political information and communication in social media and studying the reliability of political information in social media.

The mobile participation tools and applications developed along the initiative support the projects 3) "Mobile participation of citizens with protection of privacy", 4) "Televised Debates in Germany", 5) "Mobilization of right-wing parties against Europe" and 6) "Personalization of political communication". Other sub-projects outside our research focus are also supported by realizing smartphone-based test infrastructures with the use of a survey tool and special measurement tools under our development, which are described in the next chapter.

\section{5 mPart Tools in E-Participation Contexts}

In this section, we specify the mPart tools under our development and examine the advantages over existing mPart tools. We differentiate between mPart tools themselves, which are directly used for participation as described in subsection 5.2, software components cooperating with an underlying infrastructure as outlined in subsection 5.3, and online survey tools used for research in other projects of our research focus as depicted in subsection 5.4. How these features work together is outlined in the overall mPart system architecture in subsection 5.1.

\section{1 mPart System Architecture}

In order to achieve a flexible and maintainable software architecture, the mPart system architecture is separated in a framework of components ( as e.g. argued in [19, p. 394]), which are grouped and related to one another by well-defined interfaces as shown in fig. 1. The specification of the interface architecture of the mPart-APIFramework can be used for a basic evaluation of some generic properties like a generic approach, flexibility for anonymous usage and for different authentication and authorization functions, for extensibility by more modules, and for independence of end-device connections like e.g. trusted servers and simple-transport clients (see subsection 5.3). A major advantage of the architecture is that it is open for the developer community, because it supports an easy integration of new modules and special mPart tool implementations. It is also meant to be a generic framework that can be extended and adapted to special needs.

To ease system maintenance and especially to control the security features, "mPart tools" are separated from the "mPart-API framework": While mPart tools are directly invoked by users, the components of the mPart-API framework build an underlying communication infrastructure with related security and privacy support services. Some of these tools, like a mobile survey tool and a helper to secure users' privacy, enable participation directly. Others, like online survey tools, are special research tools to support researchers in their subprojects. They will work on top of the common mPart tools. 


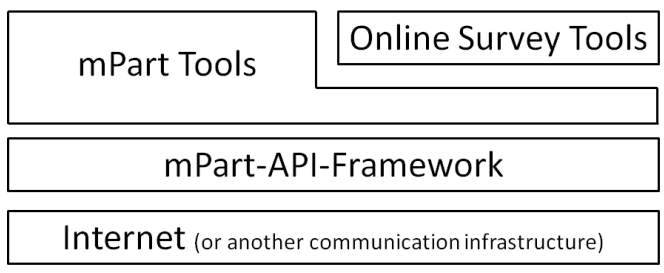

Fig. 1. Layers of the mPart System

\section{2 mPart Tools}

In this subsection, we outline the set of mPart tools developed within our project:

Mobile Survey. To run a survey is an efficient way to analyze the opinion of a bigger group of individuals, like the public opinion. A related survey tool is an essential mPart tool. We are developing an own survey system, which is already used by our project partners to collect research data. A first implementation was done by the student project "mPartOnCampus". They developed an approach for a participation platform for the relatives of our university, where we find also a complex political system. The main advantages of developing an own implementation, instead of using one from a third party, are the possibility to fulfill special requirements and integration in an application, which works on top of our own developed underlying infrastructure. For example, LimeSurvey ${ }^{18}$ is an often used survey tool. It lacks a usable interface for mobile devices and for special needs, like retriggering survey participants, when a study is ongoing over time.

Mobile Consultation. Consultation in the context of e-participation is described by Macintosh as "a two-way relationship in which citizens provide feedback to government. It is based on the prior definition of information. Governments define the issues for consultation, set the questions and manage the process, while citizens are invited to contribute their views and opinions" [11]. Consultation has been classified as an e-participation area and a number of tools have emerged to support public consultation in political decision-making (general consultation, policy consultation or consultation in lawmaking) (see e.g. [16, 18, 23, 28]). Since existing projects on consultation in political decision-making barely use mobile devices, we have developed a mobile consultation tool, which enables consultation with respect of specific consultation needs. Among others these could be the request for feedback regarding measures taken or the discussion about measures to take in the future. The mobile survey implementation will as well be used as a tool within the mobile consultation tool. First prototypes for such a tool have been implemented in the project "mPartOnCampus" at the University of Koblenz-Landau. The tool will be advanced in iterative steps.

Privacy Navigator. Security requires both, functional support by a well-designed working system, and user awareness based on a sufficient knowledge about the risks and a cautious way of acting. A typical example is trust into website operators.

18 http: / / www . limesurvey . org - last seen on 2012-13-03. 
Although a channel between a visitor of a website and a webserver is protected endto-end by SSL and certificate validation is supported by a browser, the user could circumvent the protection and manually accept untrustworthy websites. The Privacy Navigator supports user awareness of security and privacy. It offers a contextsensitive adaptation of the user and its issue to adequately secure communication channels, by choosing the channel type on the basis of the type of participation, a pragmatic analysis of the participation issue and of course additional user inputs. The design follows a simple scale for intensity of privacy, which is understood by unskilled users. Our research aim is twofold: firstly we implement the Privacy Navigator in all mPart tools in order to learn an effective way of privacy enhancing technology for mPart functions. Secondly, we will study the way of change in user behavior in order to learn how users trust the system.

\section{3 mPart-API Framework}

mPart tools do not directly use common Internet channels. We interpose an underlying infrastructure between the mPart tools and the Internet, as shown in fig. 1, encapsulated by the mPart-API framework. The mPart-API framework's tasks are

1. decouple the user functions of the mPart tools from an underlying communication infrastructure, especially from the Internet,

2. establish secure communication channels on top of the underlying infrastructure,

3. provide well defined interfaces, which are used by the mPart tools or other nodes of the mPart-API framework.

The mPart-API framework is composed of a set of interface specifications, used for implementation of the collaborating nodes and agents within the mPart system. Nodes are transmitting via machines that build an overlay network. In some cases they use other overlay networks between an underlying communication structure and themselves to establish communication channels. The design of the system allows an easy integration of new modules, which can establish communication channels on top of other communication structures.

A prototypical implementation of the framework shows the effectiveness of the architecture with an implementation on top of different communication networks. For example, $\mathrm{I}_{2} \mathrm{P}^{19}$ is an overlay network for anonymous communication and thus supports the privacy of the communication partners. [4] used an implementation of $\mathrm{I} 2 \mathrm{P}$, which is encapsulated in a generalized communication module within the mPartAPI-Framework, to realize a so called Trusted Server. A Trusted Server contains a whole implementation of the mPart-API, thus it is a part of the underlying mPartInfrastructure, consisting of many cooperating mPart nodes. It can be used as a gateway for Mobile Clients or other applications, which have no (No-TransportClient) or no complete (Simple-Transport-Client) implementation of the mPart-API, as shown in fig. 2. We evaluated the usability of the Trusted Server within the student project "mPartOnCampus".

19 http: / / www .i2p2 . de - last seen 2013-08-03. 


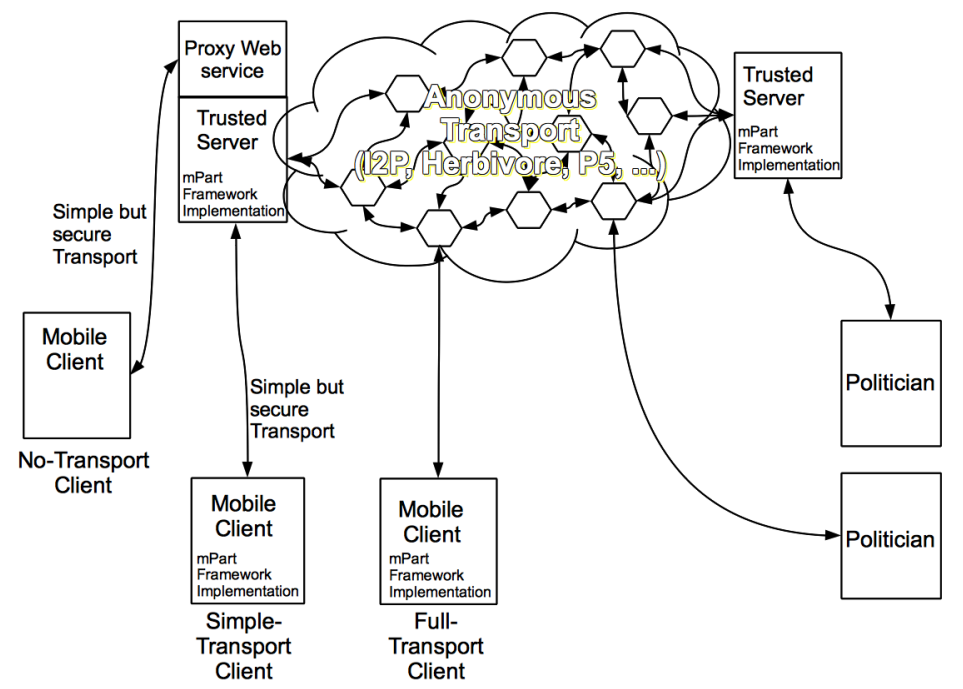

Fig. 2. mPart Usage Scenario - an implementation of the mPart-API

\subsection{Online Survey Tools}

In some subprojects of disciplines within our research focus (psychology, political theory and communication sciences), computer-aided measurement tools are used by a test-lab setup to measure human behavior by capturing user input. The following software tools are developed for this purpose:

Affective Misattribution Procedure. A psychological hypothesis supposes that recipients can be influenced by unconsciously consumed information [17]. The subprojects 5) "Mobilization of right-wing parties against Europe" and 6) "Personalization of political communication" aim to prove this effect by measuring a change of behavior. By their measurement they want to determine, which contextsensitive information results in a certain change of behavior. One method to examine this effect is the Affective Misattribution Procedure (AMP) described in [8]. We realized an AMP tool with connectivity to different survey systems, so that this procedure can be used directly in the context of a running survey.

Real Time Response Measurement. The concept of Real Time Response Measurement means immediate capturing of recipients' perception while consuming information. This method is explained and analyzed in [14]. The test environment of the subproject 4) "Televised Debates in Germany" is going to be the TV duel of the chancellor candidates in Germany in September 2013. It is suspected that investigation of data in a laboratory environment affects measurement of direct perception [3]. Our invention is the execution of such tests in a natural reception situation, e.g. respondents participate from their home being on the sofa. We will create a mobile app that provides a proper user interface for such measurements. It is expected that the study in this real-life environment will omit unwanted side-effect of a test-lab atmosphere and will make the test-results more reliable. 
All our mPart tools are currently under development. As mentioned above, the online survey tools will be used by the subprojects 5) and 6) and by other projects outside our research focus. For the time being, they are used in a first test phase by the developers. We have received first feed-back reports by the users within our research project. They report that our mPart survey tools are running more stable and produce more reliable response data than the older Flash tools they used before. For example, they appreciate that our AMP has an online interface for integration in other survey systems like, for example, the GfK system ${ }^{20}$, which implemented the surveys. Also with respect to RTR, the applicants report that their first impressions promise superior user convenience and more reliable results. A particular advantage is that larger sample sizes can be handled with less effort.

This is an indication, that we will be able to fulfill the requirements flexibility, robustness and performance. In the next project phase, a systematic evaluation will be performed including quantitative test methods.

\section{Conclusions}

The paper at hand shows that a few projects have already started to integrate the use of smartphones in e-participation applications. However, this happens in an ad-hoc way without a strategic design. We have presented an architecture that allows a flexible integration of mPart tools in an mPart-API framework. The framework offers infrastructure services such as overlay networks for anonymous communication (if needed) or authorization services (if needed) etc. through a standardized API to mPart tools. The framework is generic to enable extension of the mPart toolset with further implementations.

Examples of mPart tools under development are introduced with first reports by users (researchers in the overall multi-disciplinary project KoMePol).

Beside the technical development of the framework and the tools, our next important steps are to perform a systematic evaluation of the existing tools against the requirements: user-friendliness, acceptance, extensibility, scalability, and seamless cooperation with other participation means; and to extend the architecture with adding complementary mPart tools. Further research will be conducted to amend the architecture towards a comprehensive reference architecture for mobile participation.

Acknowledgement. This work was partially funded by the KoMePol project, which is funded by the Research Initiative (Stage II) of the State Rhineland-Palatinate. The authors express their gratitude for this interdisciplinary research opportunity.

\section{References}

1. Abramowicz, W., Karsenty, L., Moore Olmstead, P., Peinel, G., Tilsner, D., Wisniewski, M.: USE-ME.GOV (USability-drivEn open platform for MobilE GOVernment). In: Kushchu, I. (ed.) Proceedings of First European Conference on Mobile Government 2005, Brighton, UK, pp. 7-16 (2005)

20 http: / / www.gfk. com (last access 2012-26-03). 
2. Bertot, J.C., Jaeger, P.T., Munson, S., Glaisyer, T.: Social Media Technology and Government Transparency. Computer 43(11), 53-59 (2010)

3. Biocca, F., David, P., West, M.: Continuous Response Measurement (CRM). A Computerized Tool for Research on the Cognitive Processing of Communication Messages. In: Lang, A. (ed.) Measuring Psychological Responses to Media, Hillsdale, pp. 15-64 (1994)

4. Brend'amour, P.M.: Generisches Framework für die mobile Kommunikation von anonymisierten Gruppen (generic framework for mobile communication of anonymizated groups). University of Koblenz-Landau, Masterthesis (2013)

5. Charalabidis, Y., Loukis, E.: Participative Public Policy Making Through Multiple Social Media Platforms Utilization. International Journal of Electronic Government Research 8(3), 78-97 (2012)

6. Charalabidis, Y., Koussouris, S. (eds.): Empowering Open and Collaborative Governance. Technologies and Methods for Online Citizen Engagement in Public Policy Making. Springer, Heidelberg (2012)

7. Effing, R., van Hillegersberg, J., Huibers, T.: Social Media and Political Participation: Are Facebook, Twitter and YouTube Democratizing Our Political Systems? In: Tambouris, E., Macintosh, A., de Bruijn, H. (eds.) ePart 2011. LNCS, vol. 6847, pp. 25-35. Springer, Heidelberg (2011)

8. Emmer, M., Wolling, J., Vowe, G.: Changing Political Communication and Participation in Germany. Communications 36(3), 233-252 (2012)

9. Goldberg, I.A.: Pseudonymous communications infrastructure for the internet. University of California, Dissertation (2000)

10. Ergazakis, K., Metaxiotis, K., Tsitsanis, T.: A State-of-The-Art Review of Applied Forms and Areas, Tools and Technologies for e-Participation. International Journal of Electronic Government Research (IJEGR) 7(1), 1-19 (2011)

11. Macintosh, A.: Characterizing e-participation in policy-making. In: Proceedings of 37th Annual Hawaii International Conference on System Sciences (HICSS-37). IEEE Computer Society, Los Alamitos (2004)

12. Macintosh, A.: E-Democracy and E-Participation Research in Europe. In: Chen, H., et al. (eds.) Digital Government. Integrated Series in Information Systems, vol. 17, pp. 85-102. Springer, US (2008)

13. Maier, J.: Web 2.0 - Moderatorenrechte für alle? Gibt es eine E-Partizipation $2.0 \mathrm{im} \mathrm{Web}$ 2.0? In: Mitarbeit, S. (ed.) E-Partizipation: Beteiligungsprojekte im Internet, Stiftung Mitarbeit, Bonn. Beiträge zur Demokratieentwicklung, vol. (21), pp. 282-296 (2007)

14. Maier, J., Maier, M., Maurer, M., Reinemann, C., Mayer, V. (eds.): Real-Time Response Measurement in the Social Sciences. Methodological Perspectives and Applications. Frankfurt/Main (2009)

15. Olmstead, P., Peinel, G., Tilsner, D., Abramowicz, W., Bassara, A., Filipowska, A., Wisniewski, M., Żebrowski, P.: TheUSE-ME.GOV (USability-drivEn open platform for MobilE GOVernment). In: Kushchu, I. (ed.) Mobile Government: An Emerging Direction in E-Government, pp. 249-270. IGI Global, Hershey (2007)

16. Panopoulou, E., Tambouris, E., Tarabanis, K.: eParticipation Initiatives in Europe: Learning from Practitioners. In: Tambouris, E., Macintosh, A., Glassey, O. (eds.) ePart 2010. LNCS, vol. 6229, pp. 54-65. Springer, Heidelberg (2010)

17. Payne, B.K., Cheng, C.M., Govorun, O., Stewart, B.D.: An inkblot for attitudes: Affect misattribution as implicit measurement. Journal of Personality and Social Psychology 89(3), 277-293 (2005) 
18. Phang, C.W., Kankanhalli, A.: A framework of ICT exploitation for e-participation initiatives. Communications of the ACM 51(12), 128-132 (2008)

19. Reussner, R., Hasselbring, W.: Handbuch der Softwarearchitektur. Dpunkt.Verlag Heidelberg (2009)

20. Scherer, S., Wimmer, M.A.: E-participation and enterprise architecture frameworks: An analysis. Information Polity, Special Issue on Open Government and Public Participation 17(2), 147-161 (2012)

21. Scherer, S., Ventzke, S., Wimmer, M.: Evaluation of Open Source Content Management Systems for E-Participation. In: Janssen, M., et al. (eds.) Electronic Government and Electronic Participation: Joint Proceedings of Ongoing Research and Projects of EGOV and ePart 2011. Schriftenreihe Informatik, vol. 37, pp. 413-421. Linz, Trauner Druck (2011)

22. Sharma, S.K., Gupta, J.N.: Web services architecture for m-government: issues and challenges. An International Journal Electronic Government 1(4), 462-474 (2004)

23. Tambouris, E., Liotas, N., Tarabanis, K.: A Framework for Assessing E-Participation Projects and Tools. In: Proceedings of the 40th Annual Hawaii International Conference on System Sciences. IEEE Computer Society, Washington, DC (2007)

24. Trimi, S., Sheng, H.: Emerging Trends in M-Government. Communications of the ACM 51(5), 53-58 (2008)

25. United Nations, Department of Economic and Social Affairs: United Nations E-Government Survey 2012 - E-Government for the People. Report ID ST/ESA/PAS/SER.E/150, United Nations (2012), http: / / unpan1 . un. org / intradoc / groups / public / documents/un/unpan048065.pdf (last access March 24, 2013)

26. Tambouris, E., Liotas, N., Kaliviotis, D., Tarabanis, K.: A framework for scoping eParticipation. In: Proceedings of the 8th Annual International Conference on Digital Government Research (dg.o 2007). Digital Government Society of North America (2007)

27. Wimmer, M.A.: Ontology for an e-participation virtual resource centre. In: Janowski, T., Pardo, T. (eds.) Proceedings of the 1st International Conference on Theory and Practice of Electronic Governance (ICEGOV), pp. 89-98. ACM Press, New York (2007)

28. Wimmer, M.A., Bicking, M.: Method and Lessons from Evaluating the Impact of EParticipation Projects in MOMENTUM. In: Gil-Garcia, J.R. (ed.) E-Government Success Factors and Measures: Theories, Concepts, and Methodologies, pp. 213-234. IGI (2013) 